Antoni Artinov, Victor Karkhin, Pavel Khomich, Marcel Bachmann, Michael Rethmeier

\title{
Assessment of thermal cycles by combining thermo-fluid dynamics and heat conduction in keyhole mode welding processes
}

Journal article | Accepted manuscript (Postprint)

This version is available at https://doi.org/10.14279/depositonce-10544

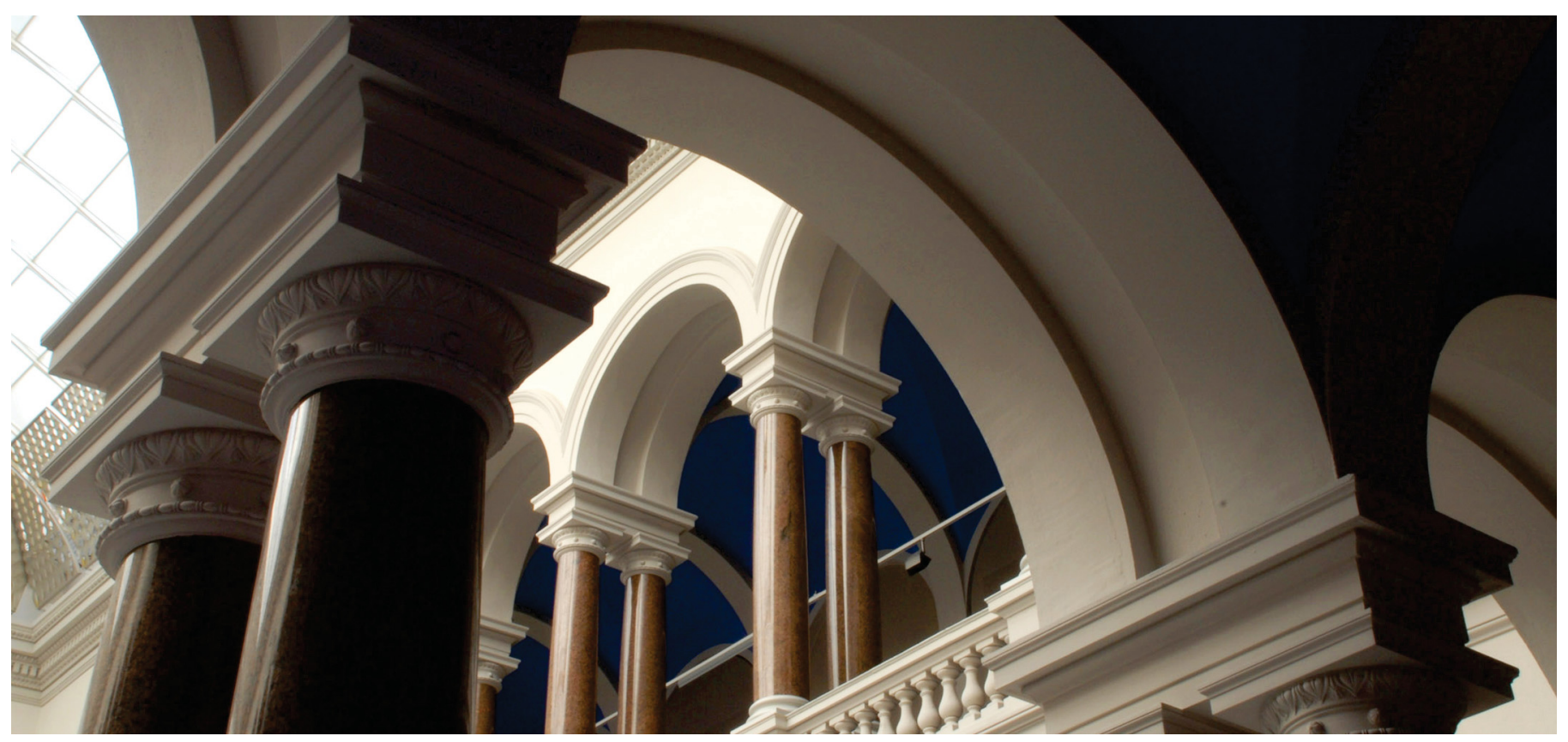

Artinov, Antoni; Karkhin, Victor; Khomich, Pavel; Bachmann, Marcel; Rethmeier, Michael (2019).

Assessment of thermal cycles by combining thermo-fluid dynamics and heat conduction in keyhole mode welding processes. International Journal of Thermal Sciences, 145, 105981.

https://doi.org/10.1016/j.ijthermalsci.2019.105981 


\title{
Assessment of thermal cycles by combining thermo-fluid dynamics and heat conduction in keyhole mode welding processes
}

\author{
Antoni Artinov ${ }^{\mathrm{a}, *}$, Victor Karkhin ${ }^{\mathrm{b}}$, Pavel Khomich ${ }^{\mathrm{b}}$, Marcel Bachmann ${ }^{\mathrm{a}}$, \\ Michael Rethmeier ${ }^{a, b, c}$ \\ ${ }^{a}$ BAM Federal Institute for Materials Research and Testing, Unter den Eichen 87, 12205 Berlin, \\ Germany \\ ${ }^{b}$ Peter the Great St. Petersburg Polytechnic University, Department of Welding and Laser \\ Technologies, Polytechnicheskaya str. 29, 195251 St. Petersburg, Russia \\ ${ }^{c}$ Department of Joining Technology, Berlin Institute of Technology, 10623 Berlin, Germany
}

\begin{abstract}
A numerical framework for simulation of the steady-state thermal behaviour in keyhole mode welding has been developed. It is based on the equivalent heat source concept and consists of two parts: computational thermo-fluid dynamics and heat conduction. The solution of the thermo-fluid dynamics problem by the finite element method for a bounded domain results in a weld pool interface geometry being the input data for a subsequent heat conduction problem solved for a workpiece by a proposed boundary element method. The main physical phenomena, such as keyhole shape, thermo-capillary and natural convection and temperature-dependent material properties are taken into consideration. The developed technique is applied to complete-penetration keyhole laser beam welding of a $15 \mathrm{~mm}$ thick low-alloyed steel plate at a welding speed of $33 \mathrm{~mm} \mathrm{~s}^{-1}$ and a laser power of $18 \mathrm{~kW}$. The fluid flow of the molten metal has a strong influence on the weld pool geometry. The thermo-capillary convection is responsible for an increase of the weld pool size near the plate surfaces and a bulge formation near the plate middle plane. The numerical and experimental molten pools, crosssectional weld dimensions and thermal cycles of the heat affected zone are in close agreement.
\end{abstract}

\footnotetext{
${ }^{*}$ Corresponding author. Tel.: +49 3081043101

Email address: Antoni. Artinov@bam.de (Antoni Artinov)
} 
Keywords: Welding process simulation, Thermo-fluid dynamics, Heat conduction, Laser beam welding, Finite element method, Boundary element method

\section{Introduction}

At the present time, the keyhole mode welding technique enables the joining of thick materials [1]-[3]. Due to the concentrated heat sources, such as a laser beam, an electron beam, a plasma jet, and the mechanical effects of the gas and the metal vapour a narrow and deep cavity called keyhole forms.

The fitness-for-purpose prediction of a welded joint requires data on the local microstructure and mechanical properties which are conditioned by the local thermal cycle of the metal. A formulation of the heat conduction problem includes welding conditions which have to be expressed in terms of (1) a heat input or (2) a temperature. In the first approach two different heat source models can be used in order to predict the thermal cycle of the welding process: concentrated and nonconcentrated. Here a distinction of the idealised heat source is made according to whether the heat input is concentrated and uniformly distributed, e.g. a point, line or plane heat source [4]-[8], or concentrated and non-uniformly distributed [9]. The non-concentrated heat sources are split into two groups: distributed over a surface, e.g. disc, cylinder, cone, strip, etc. [6]-[8],[10] or over a volume, e.g. cylinder, semi-infinite body, etc. [11]-[13]. Both groups can use a uniform or non-uniform distribution, e.g. a Gaussian, exponential, parabolic distribution, etc. [12], [14]. In the second approach, the temperature is prescribed in fixed points, e.g. within a cylindrical surface [10], [15], conical surface, etc. [16, 17].

The critical point in the formulation of the heat conduction problem is how the welding conditions have to be taken into account. In general, the total power of the welding source $q_{\text {gross }}$ can be easily measured. However, the net power $q_{\text {eff }}$ and the power distribution on the workpiece surface are poorly known. Strictly speaking, the object of modelling should include simultaneously the heat source, the metal vapour, the deformed heat source - liquid interface, the molten pool and the solid with allowance for different occurring physical phenomena, such as vaporization, radiation, thermo-capillary and natural convection, vapor induced shear stresses, phase transformations, etc. [18]-[20]. The consideration of these highly nonlinear and strongly coupled effects requires a multi-scale simulation [21]-[23]. This kind of modelling is limited through computational resources and time and therefore remains highly challenging [24]-[26]. One solution method to this problem is proposed by the concept of the so-called equivalent heat source 
(EHS) $[16,17]$. It is based on the postulate that all heat source parameters required for the simulation of the heat propagation outside the weld pool are included into the solid-liquid interface, defined by the isotherm of the solidus temperature $T_{S}$. Therefore, in order to find the temperature field around the molten pool, it is sufficient to specify the geometry of the solidus interface in time and space. This interface can be obtained by a simulation or an experimental procedure. The concept of the EHS was used in the early sixties to solve 2D problems by the finite difference method (FDM) [27]. During the last two decades, also the 3D case of the problem is investigated by applying the FDM [28] and more recently the finite element method (FEM) [17].

\section{Nomenclature}

$\begin{array}{lll}\text { Symbol } & \text { Unit } & \text { Meaning } \\ a & \mathrm{~m}^{2} \mathrm{~s}^{-1} & \text { thermal diffusivity } \\ \mathrm{Bi} & - & \text { Biot number } \\ C_{\varepsilon_{1}} & - & \text { turbulent model constant, see [32] } \\ C_{\varepsilon_{2}} & - & \text { turbulent model constant, see [32] } \\ C_{\mu} & - & \text { turbulent model constant, see [32] } \\ c & \mathrm{~J} \mathrm{~kg}^{-1} \mathrm{~K}^{-1} & \text { specific heat capacity } \\ c_{1} & \mathrm{~kg} \mathrm{~m}^{-3} \mathrm{~s}^{-1} & \text { model constant, see [34] } \\ c_{2} & - & \text { model constant, see [34] } \\ \mathbf{F} & \mathrm{kg} \mathrm{m}^{-2} \mathrm{~s}^{-2} & \text { source term, see [34] } \\ f_{L} & - & \text { liquid fraction } \\ G & \mathrm{~K} \mathrm{~W}^{-1} & \text { Green's function } \\ \mathbf{g} & \mathrm{m} \mathrm{s}^{-2} & \text { gravity acceleration } \\ H & \mathrm{~J} \mathrm{~kg}^{-1} & \text { specific enthalpy } \\ h & \mathrm{~m} & \text { plate thickness } \\ \mathbf{I} & - & \text { identity matrix } \\ \mathrm{K}_{0} & - & \text { modified Bessel function of second kind of order zero } \\ l & \mathrm{~m} & \text { domain length } \\ m & - & \text { running index } \\ n & - & \text { running index } \\ \mathbf{n} & - & \text { outward unit normal vector } \\ P_{\kappa} & \mathrm{kg} \mathrm{m}^{-1} \mathrm{~s}^{-3} & \text { turbulent production term } \\ p & \mathrm{~Pa} & \text { pressure } \\ p_{0} & \mathrm{~Pa}_{2} & \text { atmospheric pressure } \\ q_{2} & \mathrm{~W} \mathrm{~m} & \text { area-specific heat power density, heat flow density } \\ & & \end{array}$




$\begin{array}{lll}q_{e f f} & \mathrm{~W} & \text { net (effective) power of the heat source } \\ q_{g r o s s} & \mathrm{~W} & \text { gross heat source power } \\ R & \mathrm{~m} & \text { radius in space } \\ r & \mathrm{~m} & \text { radius in plane } \\ \top & - & \text { transponse operator } \\ T & \mathrm{~K} & \text { temperature } \\ T_{0} & \mathrm{~K} & \text { initial and ambient temperature } \\ T_{e v} & \mathrm{~K} & \text { evaporation temperature } \\ T_{L} & \mathrm{~K} & \text { liquidus temperature } \\ T_{\mathrm{max}} & \mathrm{K} & \text { peak temperature } \\ T_{m e l t} & \mathrm{~K} & \text { melting temperature } \\ T_{S} & \mathrm{~K} & \text { solidus temperature } \\ \mathbf{u} & \mathrm{m} \mathrm{s} & \text { fluid velocity vector } \\ u^{\prime} & \mathrm{m} & \text { independent parameter of the function } B_{k} \\ u_{x}, u_{y}, u_{z} & \mathrm{~m} \mathrm{~s}{ }^{-1} & \text { components of the velocity vector } \\ \mathbf{v} & \mathrm{m} \mathrm{s} & \text { travel speed of the heat source (welding speed) } \\ w & \mathrm{~m} & \text { domain width } \\ x & \mathrm{~m} & \text { longitudinal axis in the welding direction } \\ x, y, z & \mathrm{~m} & \text { Cartesian frame } \\ y & \mathrm{~m} & \text { space coordinate in the weld-transverse direction } \\ z & \mathrm{~m} & \text { space coordinate in the thickness direction of the plate }\end{array}$

$\begin{array}{lll}\text { Greek symbol } & \text { Unit } & \text { Meaning } \\ \alpha & \mathrm{W} \mathrm{m}^{-2} \mathrm{~K}^{-1} & \text { surface heat transfer coefficient } \\ \beta & \mathrm{K}^{-1} & \text { volumetric thermal expansion coefficient } \\ \Gamma & \mathrm{m}^{2} & \text { weld pool interface } \\ \gamma & \mathrm{Nm}^{-1} & \text { surface tension } \\ \partial \gamma / \partial T & \mathrm{Nm}^{-1} \mathrm{~K}^{-1} & \text { Marangoni coefficient } \\ \varepsilon & \mathrm{m}^{2} \mathrm{~s}^{-3} & \text { turbulent dissipation rate } \\ \kappa & \mathrm{m}^{2} \mathrm{~s}^{-2} & \text { turbulent kinetic energy } \\ \lambda & \mathrm{W} \mathrm{m}^{-1} \mathrm{~K}^{-1} & \text { thermal conductivity } \\ \mu & \mathrm{Pas} & \text { dynamic viscosity } \\ \mu_{T} & \mathrm{Pas} & \text { turbulent viscosity } \\ \mu_{k} & - & \text { positive roots, see Eq. (13) } \\ \xi, \eta, \zeta & \mathrm{m} & \text { coordinate of the heat sources } \\ \rho & \mathrm{kg} \mathrm{m} & \text { mass density } \\ \sigma_{\varepsilon} & - & \text { turbulent model constant, see [32] } \\ \sigma_{\kappa} & - & \text { turbulent model constant, see [32] }\end{array}$




\section{Abbreviations}

$\begin{array}{ll}\text { BEM } & \text { boundary element method } \\ \text { CFD } & \text { computational fluid dynamics } \\ \text { EHS } & \text { equivalent heat source } \\ \text { FDM } & \text { finite difference method } \\ \text { FEM } & \text { finite element method } \\ \text { HAZ } & \text { heat affected zone } \\ L & \text { liquid } \\ S & \text { solid }\end{array}$

Another well-known concept of the so-called apparent heat source is close to that of the EHS by means of its physical interpretation. Here beside the real heat source, fictitious heat sources are added into the weld pool in such a way as to achieve an agreement between the calculated and the desired values: peak temperature at the weld pool interface, thermal cycles at specific fixed points, etc. The unknown parameters of the fictitious heat sources are sought by an inverse modelling approach. This concept offers a number of advantages when solving the heat conduction problem by a functional-analytical method [29, 30]. In the case of using numerical methods, such as FEM, FDM or the boundary element method (BEM) the concept of the EHS becomes more feasible.

As mentioned the coupled heat source - molten pool - workpiece problem still represents a challenge and its tackling faces insurmountable obstacles. Decoupling this multi-scale task would allow approaching the problem successively and obtain a solution within a reasonable computing time without the need for a high-performance computing system even for large scale systems. Hence, the methodological task of decoupling has to be further analysed and improved.

The aim of the presented study is to develop a more suitable approach for calculating the thermal cycles of the keyhole mode welding process, taking into account the most important physical phenomena, such as thermo-capillary and natural convection, latent heat of phase transformations and temperature-dependent material properties. The proposed approach is based on the concept of the EHS. The numerical results are compared with measurements of the weld-pool shape and the thermal cycles within the heat affected zone (HAZ) of the weld and show a good correlation. 


\section{Theory}

It is a well-known fact that the physics behind the keyhole mode welding process is very complicated. It includes the following main physical aspects: keyhole formation, thermo-capillary and natural convection of the liquid metal, heat conduction in the weld pool and in the solid part and surface heat transfer, see Fig. 1.

The corresponding problem is strongly coupled and highly non-linear. Hence its tackling remains challinging [26]. In order to make the solution of this coupled problem feasible it is divided in the sequence of separate problems on the basis of the EHS concept, see Fig. 2. Thus the energy of the heat source absorbed by the body is the EHS governing the formation of the keyhole, the keyhole shape and surface temperature define then an EHS determining the weld pool boundary and in its turn the weld pool defines an EHS governing the heat conduction in the solid part of the material. The dashed frame in Fig. 2 shows the problems solved in this study, including a computational thermo-fluid dynamics (CFD) model for the weld pool and surroundings and a heat conduction model for the solid material outside

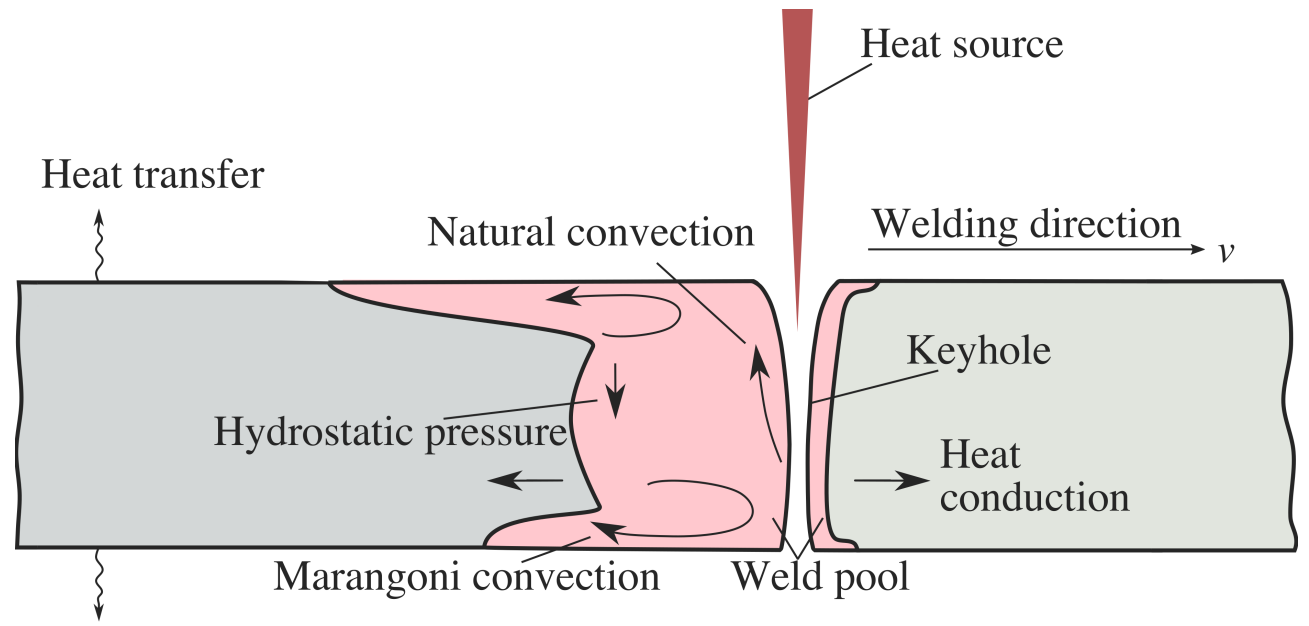

Figure 1: Schematic of the keyhole mode welding process with relevant physical phenomena

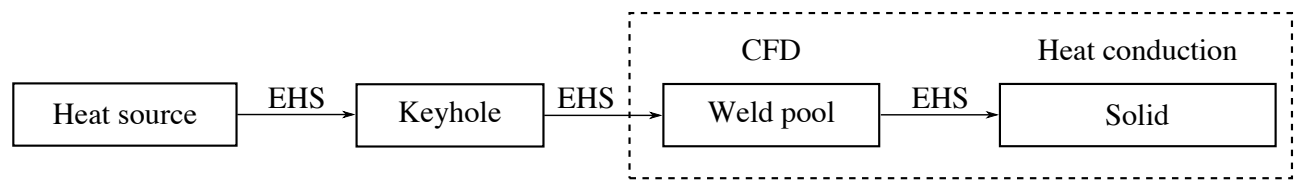

Figure 2: Representation of the coupled problem as a sequence of independent processes decoupled due to equivalent heat sources 
the weld pool. Hence, there are two computational domains in the simulation. Hereby the CFD domain is bounded and has the length $l$, the width $w$ and the thickness $h$, see Fig. 3. It is placed inside the computational domain of the heat conduction model which is an unbounded plate of the same thickness $h$. Both domains exploit a symmetry condition so that each domain represents only half of the real part to be modelled. The assumptions and formulations of the modelled problems are given below.

\subsection{Thermo-fluid dynamics}

The basic assumptions for the coupled heat transfer and fluid flow simulation of the welding process are given as follows:

- The heat source moves along the $x$-axis with a constant velocity $v$ (Fig. 3).

- Quasi-steady-state approach is used to describe the temperature and fluid velocity fields. Therefore transient phenomena, such as keyhole formation at the weld start and keyhole closing at the weld end are not included in the model.

- A fixed keyhole geometry is used in the model based on the assumption that the recoil pressure in the keyhole is perfectly balanced by the surface tensions forces. Thus the oscillations of the keyhole surface and their interaction with the molten material in the weld pool are neglected. Based on the assumption that the temperature inside the keyhole should be at least equal or higher than the evaporation temperature of the material, since the material inside the keyhole vaporises, its surface temperature is replaced by the evaporation temperature.

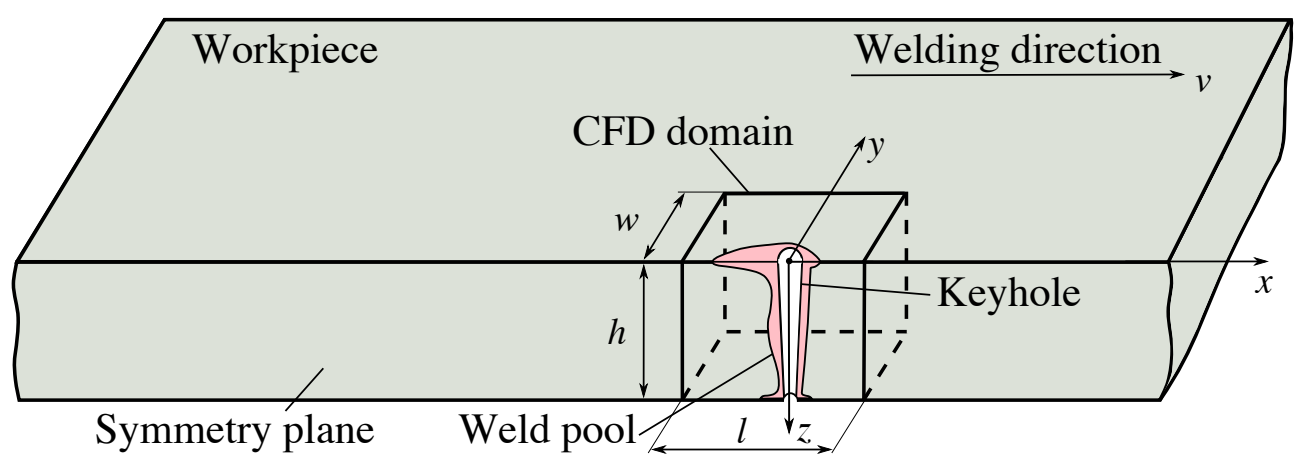

Figure 3: Moving keyhole and computational fluid dynamics domain in the plate 
- Free-slip boundary condition on the keyhole surface is valid.

- The liquid is incompressible.

- The Boussinesq approximation is used to model the impact of the density deviation caused by the temperature difference in the molten material [31].

- The turbulent flow behaviour is described by combining the steady-state Reynolds-averaged-Navier-Stokes equations with the standard $\kappa-\varepsilon$ turbulence model [32].

The mathematical formulation of the CFD problem under the assumptions made was used in similar studies and is presented below [17, 33]. In this simulation setup, the workpiece moves relative to the origin of the Cartesian coordinate system which coincides with the origin of the heat source (fixed keyhole).

- Mass conservation equation

$$
\nabla \cdot \mathbf{u}=0
$$

where $\mathbf{u}=\left(u_{x}, u_{y}, u_{z}\right)$ is the fluid velocity vector.

- Momentum conservation

$$
\rho(\mathbf{u} \cdot \nabla) \mathbf{u}=\nabla \cdot\left[-p \mathbf{I}+\left(\mu+\mu_{T}\right)\left(\nabla \mathbf{u}+(\nabla \mathbf{u})^{\top}\right)-\frac{2}{3} \rho \kappa \mathbf{I}\right]+\mathbf{F}
$$

where $\rho$ is the density, $p$ is the pressure, $\mathbf{I}$ is the identity matrix, $\mu$ is the dynamic viscosity, $\mu_{T}$ is the eddy viscosity, also known as the turbulent viscosity, superscript $T$ denotes the transpose of a matrix and the source term $\mathbf{F}$ is defined as follows:

$$
\mathbf{F}=-\rho \mathbf{g} \beta\left(T-T_{m e l t}\right)-c_{1} \frac{\left(1-f_{L}\right)^{2}}{f_{L}^{3}+c_{2}}(\mathbf{u}-\mathbf{v}) .
$$

Here $\mathbf{g}$ is the gravity acceleration, $\beta$ is the volumetric thermal expansion coefficient, $T_{\text {melt }}$ is the melting temperature defined as $T_{m e l t}=\left(T_{S}+T_{L}\right) / 2$ and $\mathbf{v}$ is the welding speed vector. The computational constants $c_{1}$ and $c_{2}$ are chosen to be very large $\left(\sim 1 \times 10^{6} \mathrm{~kg} \mathrm{~m}^{-3} \mathrm{~s}^{-1}\right)$ for the deceleration of the flow and very small $\left(\sim 1 \times 10^{-3}\right)$ to avoid division by zero, respectively. The function $f_{L}$ represents the liquid fraction in the element and is defined as follows:

$$
f_{L}=\left\{\begin{array}{ccc}
0 & \text { for } & T<T_{S} \\
\frac{T-T_{S}}{T_{L}-T_{S}} & \text { for } & T_{S} \leq T \leq T_{L} \\
1 & \text { for } & T>T_{L}
\end{array}\right.
$$


The first term on the right-hand side of Eq. (3) accounts for the buoyancy force. The second term is defined in such a way that the momentum equation is forced to mimic the Carman-Kozeny equations, describing a flow in a dencdritic mushy region [34].

- The transport equation for the kinetic energy $\kappa$ and the turbulent dissipation rate $\varepsilon$ read [35]:

$$
\begin{gathered}
\rho(\mathbf{u} \cdot \nabla) \kappa=\nabla \cdot\left[\left(\mu+\frac{\mu_{T}}{\sigma_{\kappa}}\right) \nabla \kappa\right]+P_{\kappa}-\rho \varepsilon, \\
\rho(\mathbf{u} \cdot \nabla) \varepsilon=\nabla \cdot\left[\left(\mu+\frac{\mu_{T}}{\sigma_{\varepsilon}}\right) \nabla \varepsilon\right]+C_{\varepsilon_{1}} \frac{\varepsilon}{\kappa} P_{\kappa}-C_{\varepsilon_{2}} \rho \frac{\varepsilon^{2}}{\kappa}
\end{gathered}
$$

where the turbulent viscosity $\mu_{T}$ and the turbulent production term $P_{\kappa}$ are given as follows:

$$
\begin{gathered}
\mu_{T}=\rho C_{\mu} \frac{\kappa^{2}}{\varepsilon}, \\
P_{\kappa}=\mu_{T}\left[\nabla \mathbf{u}:\left(\nabla \mathbf{u}+(\nabla \mathbf{u})^{\top}\right)\right],
\end{gathered}
$$

all the remaining model constants $C_{\mu}, C_{\varepsilon_{1}}, C_{\varepsilon_{2}}, \sigma_{\varepsilon}, \sigma_{\kappa}$ are designed to satisfy the physical consistency of the turbulence model. These are determined from experimental data and taken from the literature [32].

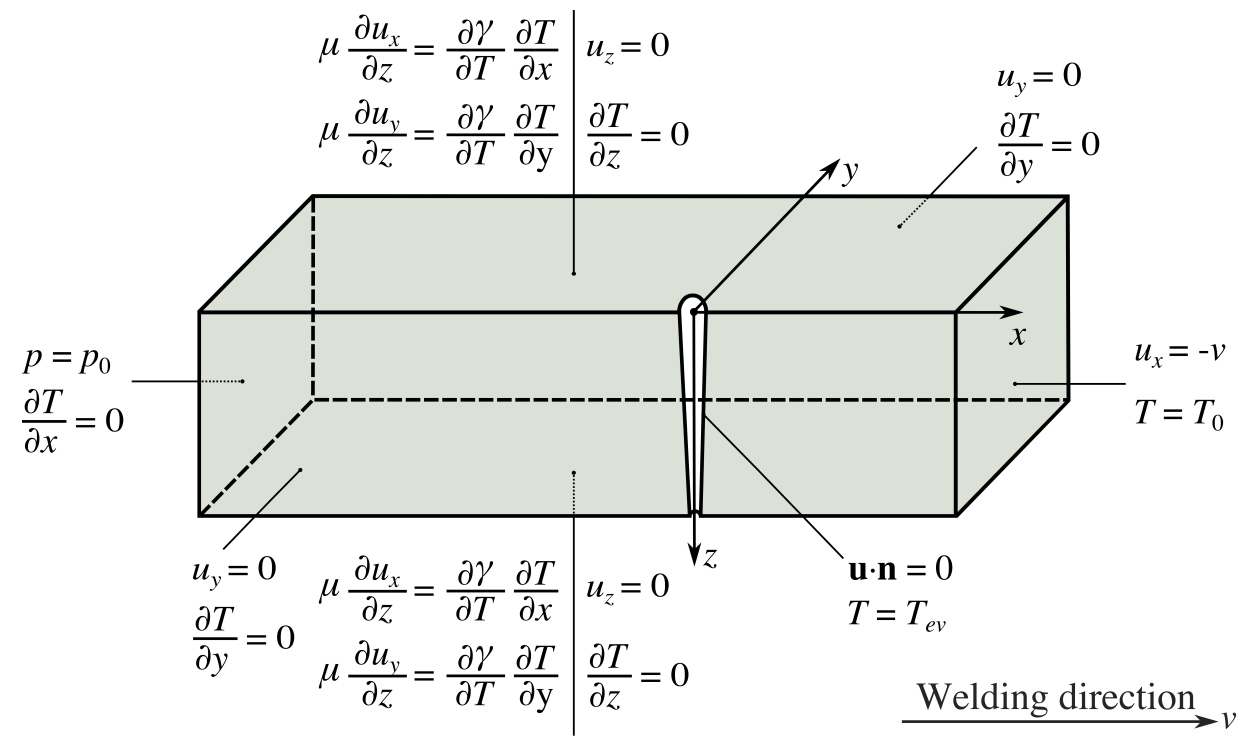

Figure 4: Boundary conditions for the thermo-fluid dynamics simulation 
- Energy conservation equation

$$
\nabla \cdot(\lambda \nabla T)-\rho c \mathbf{u} \cdot \nabla T=0
$$

where $\lambda$ is the thermal conductivity and $c$ the specific heat capacity. Here $c$ accounts for the latent heat of solid-solid and solid-liquid phase transformations. By definition $c=\mathrm{d} H / \mathrm{d} T$ with $H$ as the specific enthalpy.

The boundary conditions for the CFD problem are shown in Fig. 4. On the upper and lower surface of the plate, a Marangoni boundary condition was applied to consider the fluid flow due to the temperature-dependent surface tension [36]. The side boundary $y=w$ is considered to be heat-impermeable $(\partial T / \partial y=0)$, which is reasonable for the CFD domain, because of the high relation of the domain width to the weld pool width.

By using such an approach it should be ensured that the amount of energy absorbed by the workpiece from the keyhole surface has approximately an expected value according to the standard efficiency values of the process. This means, that the surface integral of the heat fluxes through the keyhole surface should result in an energy amount in the range of $60 \%$ to $80 \%$ of the input power. The simplified flowchart of the fluid dynamics computation is shown in Fig. 5. All equations are solved by the commercial finite element software COMSOL Multiphysics 5.0. Detailed data on the algorithm are presented in [17].

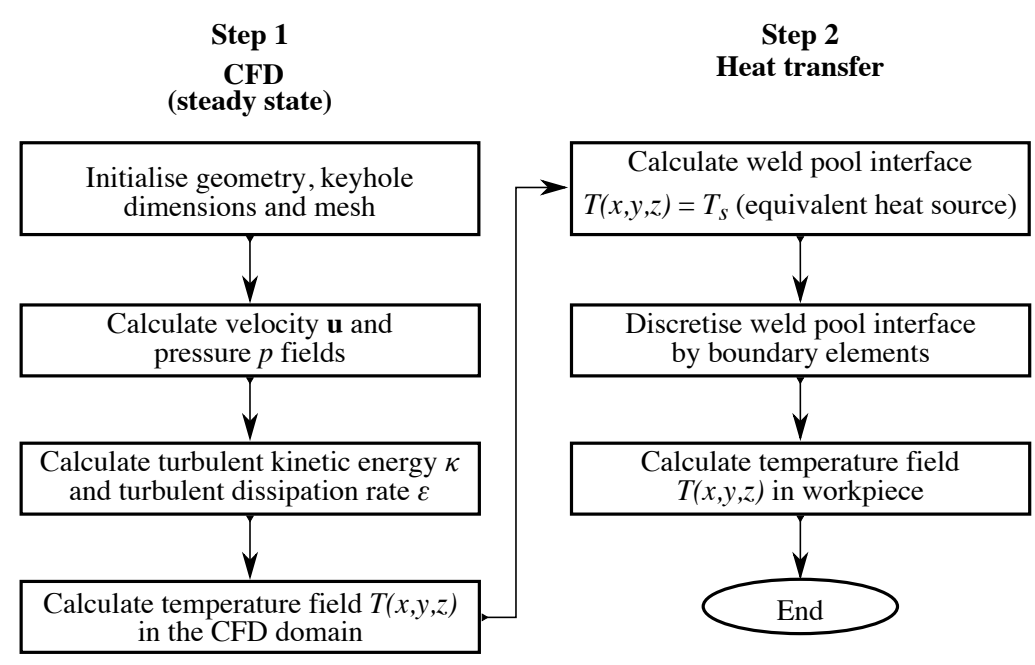

Figure 5: Simplified flowchart of the two-step simulation: calculation of the fluid dynamics and calculation of the temperature field in the workpiece 


\subsection{Heat conduction}

The following assumptions are made:

- The object to be investigated is a solid part $S$ of a homogeneous unbounded plate of thickness $h$, see Fig. 6 .

- The thermophysical properties (thermal conductivity $\lambda$, specific heat capacity $c$, density $\rho$, thermal diffusivity $a=\lambda / c \rho$, coefficients of heat transfer at upper and lower plate surfaces $\alpha_{1}$ and $\alpha_{2}$ ) are temperature-independent. The molten pool $L$ moves with a constant speed $v$ along the $x$-axis, see Fig. 6.

- The coordinates and the temperature of the weld pool boundary (the interface between the weld pool and the unmelted metal) $\Gamma$ are known and constant, and the temperature field is steady, see Fig. 6.

- The heat energy is introduced only through the molten pool; the initial and ambient temperature $T_{0}$ is constant.

Then the 3D linear heat conduction equation for a thick plate (slab) in a moving reference frame takes the form:

$$
a \nabla^{2} T+v \frac{\partial T}{\partial x}=0
$$

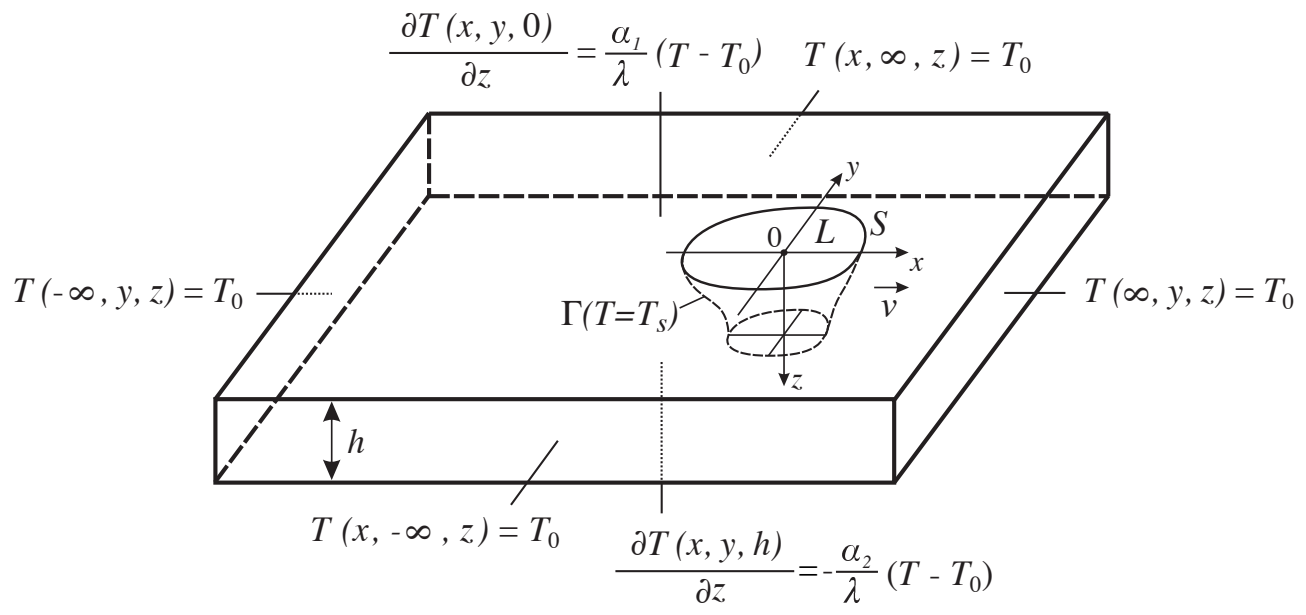

Figure 6: Boundary conditions for the heat conduction simulation 
The boundary conditions for the unbounded solid domain $S$ with a hole $L$ inside are written in Fig. 6 . The temperature of the hole surface $\Gamma$ equals the solidus temperature $T_{S}$, the temperature far away from the hole equals the initial temperature $T_{0}$ and the heat transfer at the upper and lower surfaces obeys Newton's law, see Fig. 6.

The boundary element method is applied to solve the stated problem [37]. It offers the advantage, in comparison to the FEM and the FDM, of lowering the problem dimensionality by one. The investigated homogeneous volume $S$ is expanded up to the unbounded domain $S+L$ of similar material properties. As next fictitious heat sources with unknown distribution of the area-specific power density $q_{2}(\xi, \eta, \zeta)$ are introduced at the surface $\Gamma$ in the domain $S+L$. Here $\xi, \eta, \zeta$ represent the coordinates for the corresponding heat sources. Note that the origins of the coordinates $x, y, z$ and $\xi, \eta, \zeta$ coincide, see Fig. 7 . Then the temperature increase at any point under study is determined by combined action of all fictitious heat sources by integration along the surface $\Gamma(\xi, \eta, \zeta)$ [38]:

$$
T(x, y, z)-T_{0}=\int_{\Gamma} q_{2}(\xi, \eta, \zeta) G(x, y, z, \xi, \eta, \zeta) \mathrm{d} \Gamma(\xi, \eta, \zeta)
$$

where $G(x, y, z, \xi, \eta, \zeta)$ is the fundamental solution of Eq. (10), also known as the Green's function. The function $G$ corresponds to the temperature at any point $x, y, z$ due to a point source at $\xi, \eta, \zeta$. The Green's function $G(x, y, z, \xi, \eta, \zeta)$ can

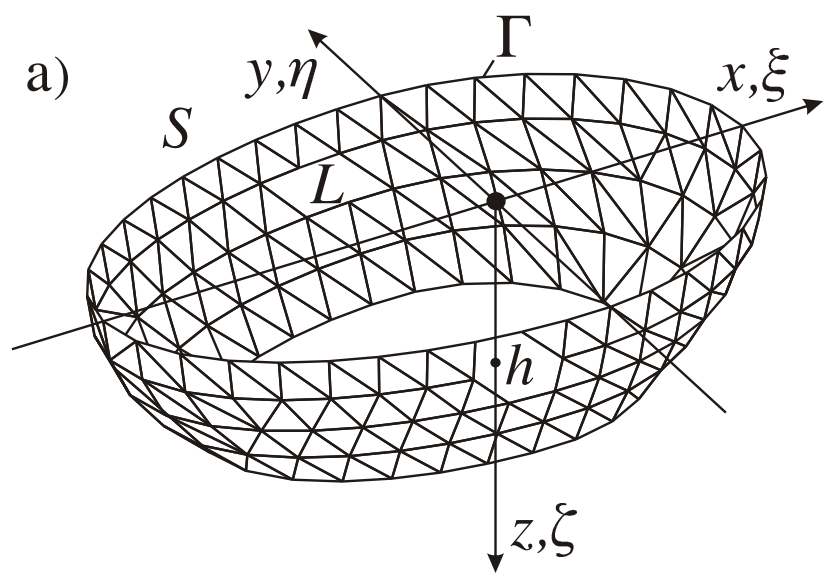

b)

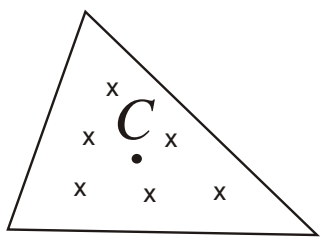

Figure 7: a) Schematic of the weld pool interface divided into boundary elements. b) An exemplary triangular element with a centre of gravity (point $C$ ) and the Gaussian points of integration (marked by $\mathrm{x}$. 
be found by using the source method [38]:

$$
\begin{aligned}
G(x, y, z, \xi, \eta, \zeta)=\frac{1}{2 \pi \lambda h} \exp ( & \left.-\frac{v(x-\xi)}{2 a}\right) \sum_{k=1}^{\infty} A_{k} B_{k}(\zeta) B_{k}(z) \times \\
& \times \mathrm{K}_{0}\left(\frac{v r}{2 a}\left[1+\left(\mu_{k} \frac{2 a}{v h}\right)^{2}\right]^{1 / 2}\right)
\end{aligned}
$$

where

$$
\begin{gathered}
r=\left[(x-\xi)^{2}+(v-\eta)^{2}\right]^{1 / 2}, \\
A_{k}=\frac{2}{\left(\mu_{k}+\mathrm{Bi}_{1}^{2}\right)\left(1+\frac{\mathrm{Bi}_{2}^{2}}{\mu_{k}^{2}+\mathrm{Bi}_{2}^{2}}\right)+\mathrm{Bi}_{1}^{2}} \\
B_{k}\left(u^{\prime}\right)=\mu_{k} \cos \left(\mu_{k} \frac{u^{\prime}}{h}\right)+\mathrm{Bi}_{1} \sin \left(\mu_{k} \frac{u^{\prime}}{h}\right) .
\end{gathered}
$$

Here $\mathrm{K}_{0}$ is the modified Bessel function of second kind of order zero, $\mathrm{Bi}$ is the Biot number, $u^{\prime}$ is the independent parameter of the function $B_{k}$, and $\mu_{k}$ are the positive roots of the following equation:

$$
\begin{gathered}
\cot (\mu)=\frac{\mu^{2}-\mathrm{Bi}_{1} \mathrm{Bi}_{2}}{\mu\left(\mathrm{Bi}_{1}+\mathrm{Bi}_{2}\right)}, \\
\mathrm{Bi}_{1}=\frac{\alpha_{1} h}{\lambda} \text { and } \mathrm{Bi}_{2}=\frac{\alpha_{2} h}{\lambda} .
\end{gathered}
$$

If the upper and the bottom surface of the plate are treated as adiabatic ( $\alpha_{1}=\alpha_{2}=$ 0 ) then the Green's function is represented as [38]:

$$
G(x, y, z, \xi, \eta, \zeta)=\frac{1}{4 \pi \lambda} \exp \left(-\frac{v(x-\xi)}{2 a}\right) \sum_{i=-\infty}^{\infty} \sum_{j=-1,1} \frac{1}{R_{i, j}} \exp \left(-\frac{v R_{i, j}}{2 a}\right)
$$

with

$$
R_{i, j}=\left[(x-\xi)^{2}+(y-\eta)^{2}+(z-j \zeta-2 i h)^{2}\right]^{1 / 2}
$$

or in a Fourier series:

$$
\begin{aligned}
& G(x, y, z, \xi, \eta, \zeta)=\frac{1}{2 \pi \lambda h} \exp \left(-\frac{v(x-\xi)}{2 a}\right) \times \\
& \quad \times\left[\mathrm{K}_{0}\left(\frac{v r}{2 a}\right)+2 \sum_{i=1}^{\infty} \cos \frac{\pi i z}{h} \cos \frac{\pi i \zeta}{h} \mathrm{~K}_{0}\left(\frac{v r}{2 a} \sqrt{1+\left(\frac{2 \pi a i}{v h}\right)^{2}}\right)\right] .
\end{aligned}
$$


Finite width of the plate can be easily taken into consideration by using the method of images [38, 39].

If the workpiece shape is more complex, e.g. a T-joint, then the Green's function for a moving point source in an infinite body can be taken from [4]. However in this case to meet the boundary conditions is more difficult [40]. In order to find the unknown functions $q_{2}(\xi, \eta, \zeta)$ in Eq. (11) it is required that the temperature at the surface $\Gamma$ is coincident with the prescribed values $T_{S}$ at the boundary $\Gamma$ of the domain $S$ :

$$
\int_{\Gamma} q_{2}(\xi, \eta, \zeta) G(x, y, z, \xi, \eta, \zeta) \mathrm{d} \Gamma(\xi, \eta, \zeta)=T_{S}(\xi, \eta, \zeta)-T_{0}
$$

In practice, the exact solution of the integral equation (16) with respect to the function $q_{2}$ is impossible, therefore approximation methods have to be used. In this case, a closed curved surface $\Gamma$ can be approximated by $N$ plane triangles, see Fig. 7. Let the power distribution $q_{2 m}$ within each $m$-th triangular element be constant. Hence, the unknown function $q_{2}(\xi, \eta, \zeta)$ in Eq. (16) is replaced by a piecewise-constant function by a series of unknown values $q_{21}, q_{22}, \ldots, q_{2 N}$. These unknown values are found from the condition that the total temperature in the middle of each element (node) $C_{n}(n=1, \ldots, N)$ due to each source $q_{2 m}(m=1, \ldots, N)$ is equal to the prescribed solidus temperature $T_{S n}$. As a result, a system of $N$ linear equations with respect to the unknown $q_{2 n}$ is formed. Each $n$-th element takes the form:

$$
\sum_{m=1}^{N} q_{2 m} \int_{\Gamma_{m}} G\left(x_{C_{n}}, y_{C_{n}}, z_{C_{n}}, \xi_{m}, \eta_{m}, \zeta_{m}\right) \mathrm{d} \Gamma_{m}\left(\xi_{m}, \eta_{m}, \zeta_{m}\right)=T_{S n}-T_{0}
$$

where $x_{C_{n}}, y_{C_{n}}$ and $z_{C_{n}}$ are the coordinates of the points $C_{n}$ (the centre of the $n$ th element), see Fig. 7b. Integration over the area of each element is performed numerically [37], [41, 42].

Note that the integral in Eq. (17) is improper since the integrand has a singularity, when $x_{C_{n}}=x_{m}, y_{C_{n}}=y_{m}, z_{C_{n}}=z_{m}$. In this case, the Gauss-Legendre quadrature can be used (the Gaussian points of integration are marked by $\mathrm{x}$ in Fig. 7b.)

The system of equations (17) with respect to $q_{2 n}(n=1, \ldots, N)$ can be solved by known methods [37], [41, 42]. Using the obtained values $q_{2 n}$ the temperature at any point $x, y, z$ inside the solid can be calculated by ordinary integration:

$$
T(x, y, z)-T_{0}=\sum_{m=1}^{N} q_{2 m} \int_{\Gamma_{m}} G(x, y, z, \xi, \eta, \zeta) \mathrm{d} \Gamma(\xi, \eta, \zeta)
$$


Equation (18) enables the calculation of all characteristics of the temperature field: peak temperature $T_{\max }(y, z)$, temperature gradient $\nabla T(x, y, z)$, cooling rate $\partial T / \partial t(x, y, z)$ and thermal cycle $T(y, z, t)$, where $t$ is the time variable.

A flowchart of the calculation of the temperature field in the workpiece is shown in Fig. 5 (Step 2). The input is the weld pool interface (equivalent heat source) which is the solution of the fluid dynamics problem for the CFD domain, see Fig. 5 (Step 1).

\section{Example}

A $15 \mathrm{~mm}$ thick S355J2G3 $(0.17 \% \mathrm{C}, 1.4 \% \mathrm{Mn})$ low-alloyed steel plate is laser welded with an Ytterbium fibre laser. The keyhole mode welding process occurs under the following conditions: laser power $q_{\text {gross }}=18 \mathrm{~kW}$ and welding speed $v=33 \mathrm{~mm} \mathrm{~s}^{-1}$. The initial and ambient temperature $T_{0}$ is $298 \mathrm{~K}$ [17]. The thermo-physical properties of the material: thermal conductivity $\lambda$, heat capacity $c$ and dynamic viscosity $\mu$ are shown in Fig. 8. The rest of the material properties are presented in Table 1.

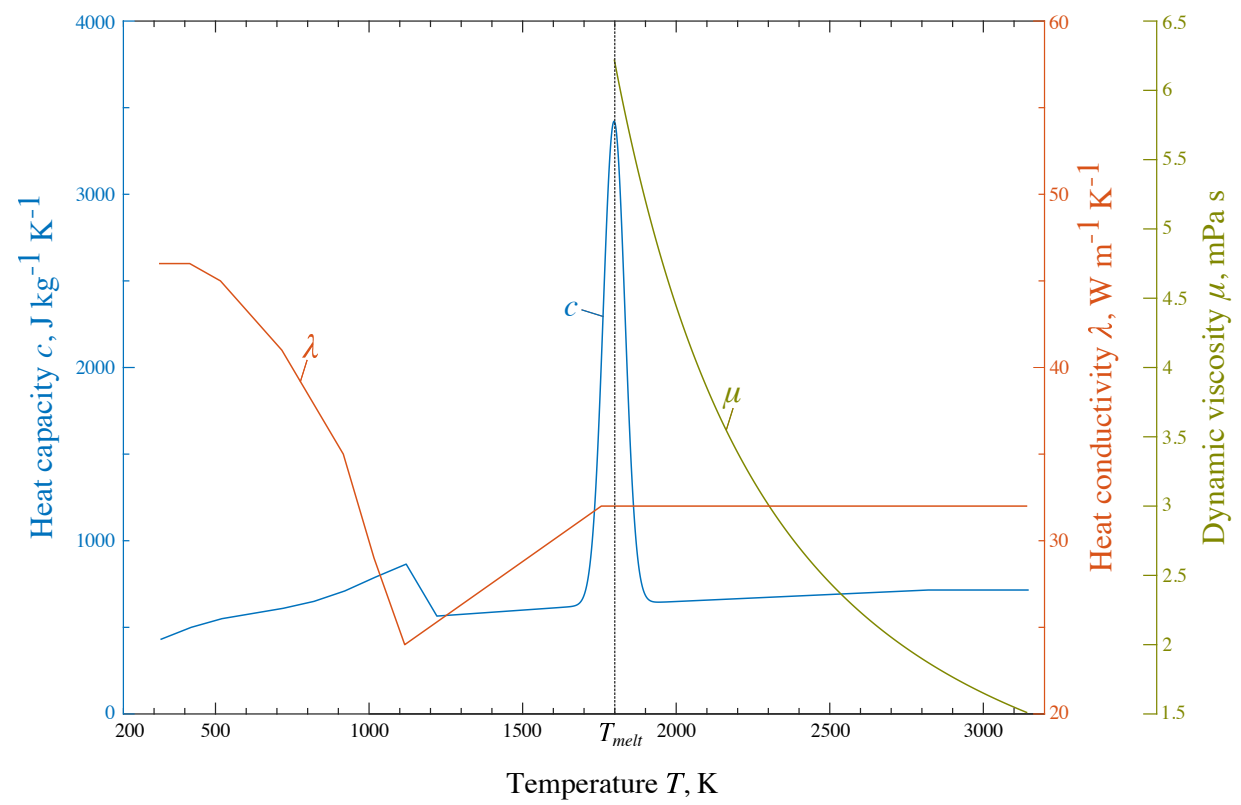

Figure 8: Temperature-dependent material properties of the low-alloyed S355J2G3 steel [43]-[46] 
Table 1: Material properties of the low-alloyed S355J2G3 steel [43]-[46]

\begin{tabular}{llll}
\hline Property & Symbol & Value & Unit \\
\hline Averaged thermal diffusivity & $a$ & 7.11 & $\mathrm{~m}^{2} \mathrm{~s}^{-1}$ \\
Averaged thermal conductivity & $\lambda$ & 34.11 & $\mathrm{~W} \mathrm{~m}^{-1} \mathrm{~K}^{-1}$ \\
Averaged specific heat capacity & $c$ & 625 & $\mathrm{~J} \mathrm{~kg}^{-1} \mathrm{~K}^{-1}$ \\
Averaged mass density & $\rho$ & 7850 & $\mathrm{~kg} \mathrm{~m}^{-3}$ \\
Averaged coefficient of heat transfer & $\alpha$ & 15 & $\mathrm{~W} \mathrm{~m}^{-2} \mathrm{~K}^{-1}$ \\
Liquidus temperature & $T_{L}$ & 1835 & $\mathrm{~K}$ \\
Melting temperature & $T_{m e l t}$ & 1800 & $\mathrm{~K}$ \\
Solidus temperature & $T_{S}$ & 1765 & $\mathrm{~K}$ \\
Evaporation temperature & $T_{e v}$ & 3100 & $\mathrm{~K}$ \\
Marangoni coefficient & $\partial \gamma / \partial T$ & $-4.3 \cdot 10^{-4}$ & $\mathrm{Nm}^{-1} \mathrm{~K}^{-1}$ \\
Coefficient of thermal expansion & $\beta$ & $1.5 \cdot 10^{-5}$ & $\mathrm{~K}^{-1}$ \\
\hline
\end{tabular}

\subsection{Verification of input data \& validation of numerical results}

In order to verify the input data (weld pool geometry) used in the proposed numerical framework and as well as to validate the obtained numerical results (quasi steady-state temperature field), welding experiments are performed. The accuracy of the numerically obtained weld pool dimensions, later on used as an EHS for the heat conduction in the solid part of the workpiece, is verified by metallographic cross-sections and an additional comparison of the weld pool length, on the top and bottom surfaces, to the length of the weld end crater from the experiments. For the validation of the calculated thermal cycles, the temperature at difference distances from the weld centerline, between $1 \mathrm{~mm}$ and $2 \mathrm{~mm}$ is measured with thermocouples of type K. A full description of the experimental set-up and procesedure can be found in [17].

\subsection{CFD simulation (Step 1)}

The computational domain for the CFD simulation has the geometric dimensions of $l \times w \times h=70 \mathrm{~mm} \times 10 \mathrm{~mm} \times 15 \mathrm{~mm}$ providing a symmetry plane at $y=0 \mathrm{~mm}$, see Fig. 3. The shape of the keyhole is approximated by a truncated right circular cone with a radii $r=0.41 \mathrm{~mm}$ at the top $(z=0 \mathrm{~mm})$ and $r=0.26 \mathrm{~mm}$ at the bottom $(z=15 \mathrm{~mm})$. The keyhole surface temperature equals the evaporation temperature $T_{e v}=3100 \mathrm{~K}$ according to the assumptions made in the model, see Section 2.1. The domain is discretised by about $1,460,000$ tetrahedral finite elements. The minimum element size used is $0.1 \mathrm{~mm}$. The finest meshing is 
a)

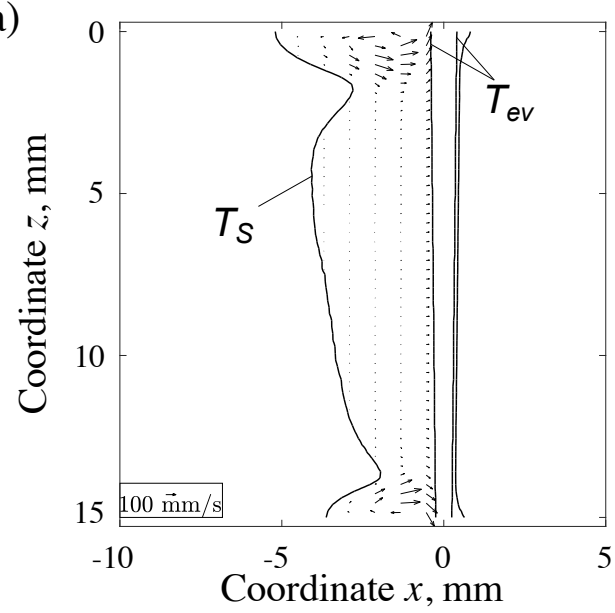

b)

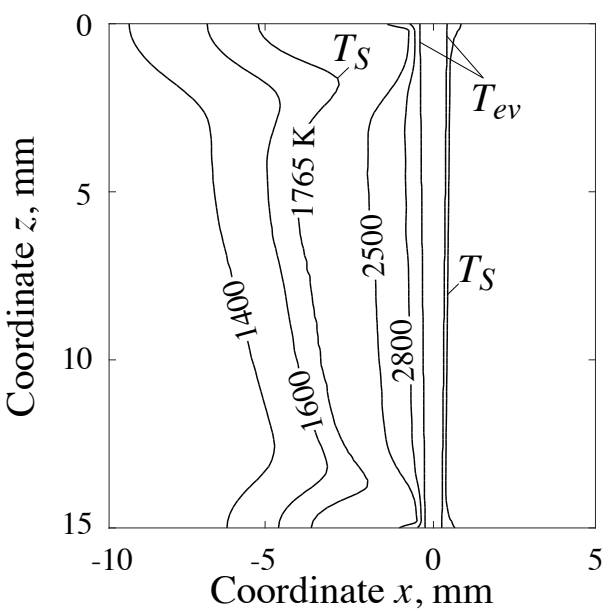

Figure 9: a) Velocity field of the liquid metal relative to the solid $\mathbf{u}-\mathbf{v}$. b) Temperature field of the symmetry plane $(y=0)$

near the keyhole surface and the free surfaces for resolving the steep temperature and velocity gradients. The turbulent model constants are as following [32]: $C_{\mu}=0.09, C_{\varepsilon_{1}}=1.44, C_{\varepsilon_{2}}=1.92, \sigma_{\kappa}=1.0$ and $\sigma_{\varepsilon}=1.3$ The detailed data on the meshing can be found in [17]. The algorithm for solving the CFD problem (Step 1) is presented in Section 2.1. As basic the finite element software COMSOL Multiphysics 5.0 is used taking into account the main relevant physical phenomena.

The steady-state velocity field of the liquid metal in reference to the solid is shown in Fig. 9a. The velocity difference $\mathbf{u}-\mathbf{v}$ characterises the flow of the liquid metal. It is seen that the weld pool is divided into three regions (upper, middle and lower). With distance from the keyhole, the temperature decreases and consequently the surface tension increases causing two vortexes. These transport the hot liquid away from the keyhole to the edge of the weld pool and form the upper and lower regions, the longer one on the upper side and the smaller one on the bottom side as a result of the reduced energy input through the conical keyhole (Fig. 9a). From the simulation results, a strong interaction between the movement of the laser source and the thermo-capillary driven vortexes is obtained leading to a teardrop shape at the upper and bottom surface of the workpiece. Additionally, it shows that a bulging in the weld pool, near the middle of the plate thickness occurs caused by the backflows on the upper and lower side due to the thermo-capillary driven flows [47]. The effect of natural convection is very small as compared to the thermo-capillary convection. The temperature distribution 


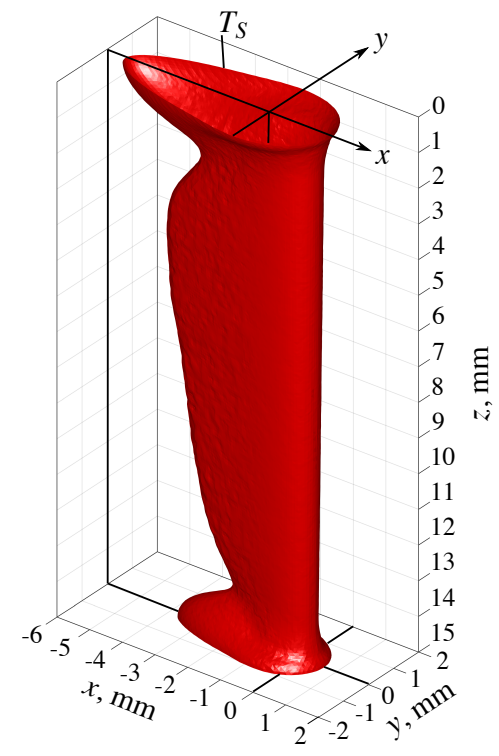

Figure 10: Weld pool interface defined by the solidus temperature $T_{S}$

behind the keyhole is formed by the flow of the melt around it (Fig. 9b). The calculated weld pool length is about $6.3 \mathrm{~mm}$ on the upper and $4.4 \mathrm{~mm}$ on the lower side, see Fig. 10. These values agree very well with the experimentally obtained values of about $6.9 \mathrm{~mm}$ and $4.6 \mathrm{~mm}$ for the weld end crater, respectively [17]. Note here that the geometrical dimensions of the crater are slightly bigger than those of the experimental weld pool due to overheating effects of the molten material once the laser is shut down, leading to further melting of material.

\subsection{BEM heat conduction simulation (Step 2)}

The weld pool interface is the main result of the solution of the CFD problem. It is used as an equivalent heat source in the heat conduction problem for the workpiece, see Fig. 10. The source surface was divided into 20,044 triangular boundary elements. The algorithm for the solution of the $3 \mathrm{D}$ heat conduction problem by the BEM is set out in Section 2.2

The obtained solution results in a heat flux $q_{2}$ across the weld pool interface. Integration of the heat flux $q_{2}$ over the interface gives an effective (net) heat source power $q_{e f f}$. The temperature distribution around the weld pool at the upper $(z=0 \mathrm{~mm})$ and lower $(z=15 \mathrm{~mm})$ surface is shown in Fig. 11. The ratio of the power $q_{e f f}$ to the total laser power $q_{\text {gross }}$ gives the heat source efficiency $\eta_{h}$ :

$$
\eta_{h}=q_{\text {eff }} / q_{\text {gross }} \approx 10900 \mathrm{~W} / 18000 \mathrm{~W}=0.6
$$


Due to the high welding speed (more precisely, the high Peclet number) the temperature gradients are very high in front of the weld pool and low behind it. The temperature distribution outside the weld in the symmetry plane $(y=0 \mathrm{~mm})$ is shown in Fig. 11. The obtained solution allows to obtain the peak temperature field $T_{\max }(y, z)$ and, consequently, to compute the weld cross-section including the HAZ (Fig. 12b). The computed weld cross-section in the heat conduction simulation is directly linked to the weld pool shape, see Section 2.2. Since the numerically calculated weld pool shape is reproduced by the BEM, the verification of the simulated weld pool shape can be done by the comparison of the cross-
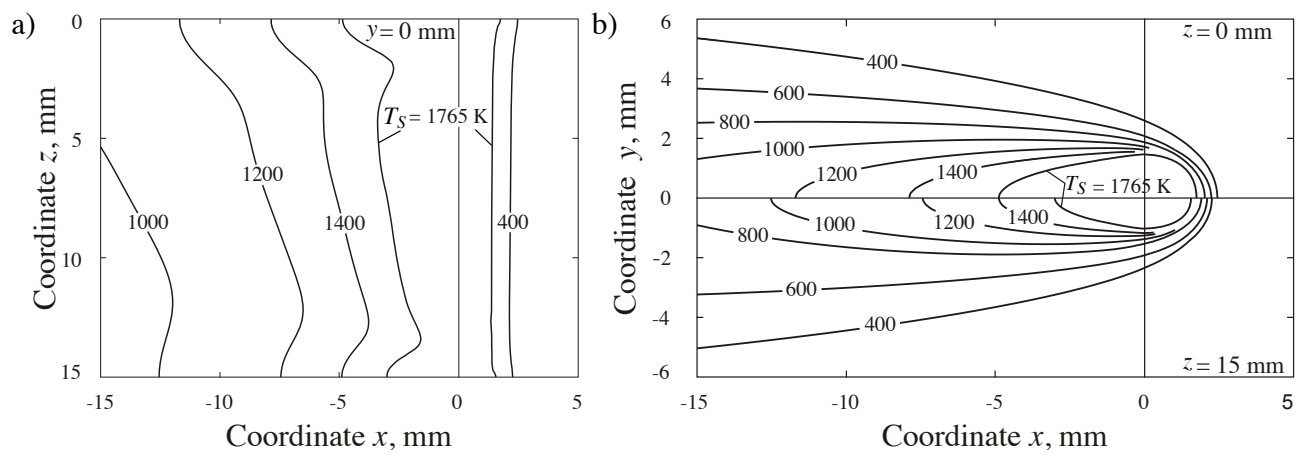

Figure 11: a) Temperature field in the longitudinal section and b) at depth $z 0 \mathrm{~mm}$ and $15 \mathrm{~mm}$

a)

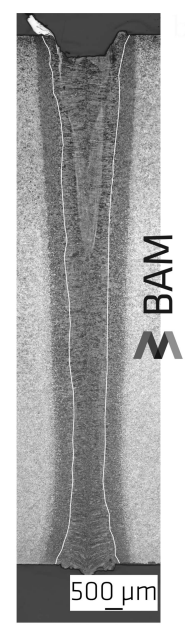

b)

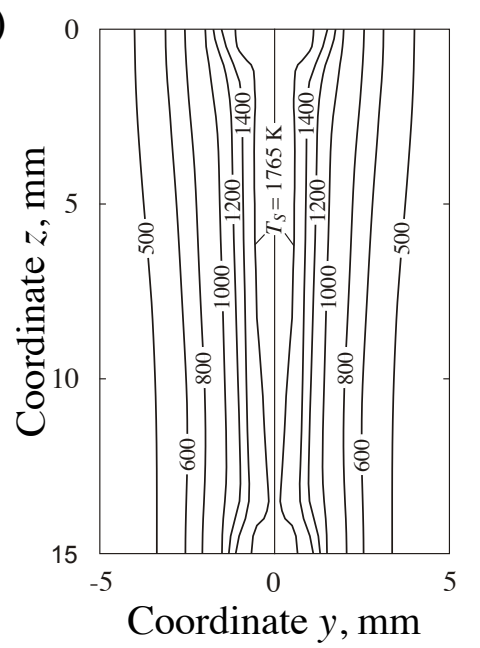

Figure 12: a) Metallographic cross-section (weld pool is outlined in white) [17]. b) Simulated temperature distribution $T(y, z)$ in the plate cross-section 
section calculated in Section 3.3 and the experimentally obtained metallographic cross-section in [17]. Note, that the reproduction of the weld pool is strongly dependent on the number of triangles used for its descritisation, see Section 2.2. Figure 12 shows good correlation of the obtained results.

The thermal cycles enable the prediction of the local microstructure and the mechanical properties of the part to be welded. Figure 13 shows the comparison of the measured and calculated thermal cycles at different distances from the sym-
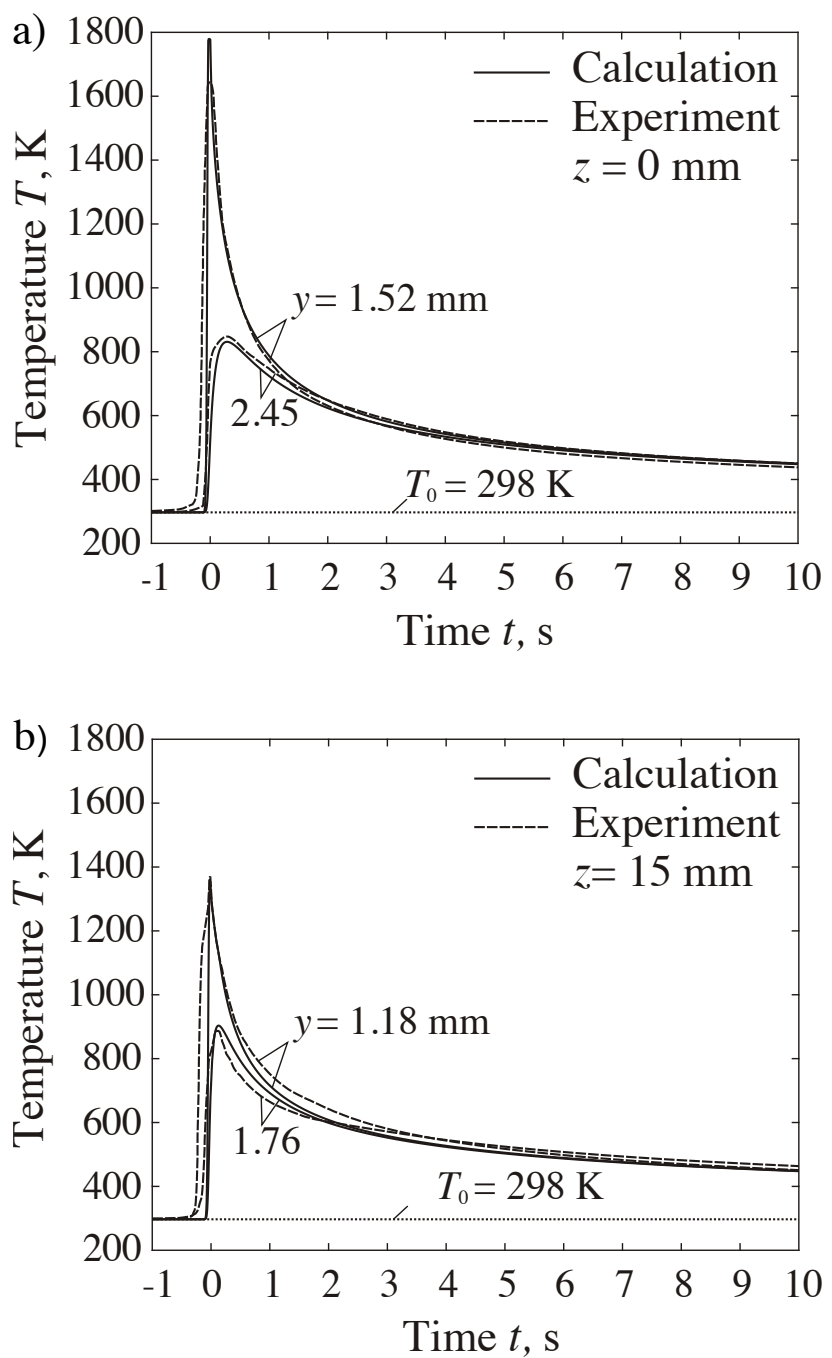

Figure 13: Comparison of the calculation and experimental thermal cycles on the upper a) and lower side b) of the plate at different distances from the weld centreline 
metry plane. The simulated thermal cycles follow from the equality $T(t, y, z)=$ $T(-x / v, y, z)$. It is evident from the curves that the numerical model captures well the thermal behaviour of the workpiece.

\section{Conclusions}

A numerical model for the assessment of the thermal cycle during keyhole mode welding is developed. It allows the consideration of different welding conditions, keyhole shape, thermo-capillary and natural convection of the molten metal and latent heat of phase transformations. Furhtermore, the accuracy of the EHS for the proposed BEM can be enhanced by taking into account other main physical phenomena.

The equivalent heat source concept permits to formulate a coupled heat source - keyhole - weld pool - solid problem as a sequence of decoupled problems of fluid dynamics and heat conduction.

The steady-state thermo-fluid dynamics problem is solved by the finite element method. The steady-state heat conduction problem is solved by the boundary element method. The proposed framework lowers the problem dimensionality by one and excludes the transient phenomena enabling the computation of the thermal cycles for large scale systems and leading to a high reduction of the computational time and effort.

The fluid flow of the molten metal shows a strong influence on the weld pool geometry. The thermo-capillary convection is responsible for the convex-concave melt pool shape due to an increase of the weld pool dimensions near the plate surfaces and a bulge formation near the middle of the plate thickness.

The calculated and experimental weld pool, cross-sectional dimensions and thermal cycles in the heat affected zone are in close agreement.

\section{Acknowledgements}

Financial funding by the Deutsche Forschungsgemeinschaft (DFG, German Research Foundation) - project Nr. 411393804 is gratefully acknowledged.

With the support of the Erasmus+ programme of the European Union. 


\section{References}

[1] Katayama, S., Mizutani, M., Kawahito, Y ., Ito, S., Sumimori, D., Fundamental research of $100 \mathrm{~kW}$ fiber laser welding technology, Proceedings of the Lasers in Manufacturing Conference (2015)

[2] Nielsen, S. E., High Power laser hybrid welding - challenges and perspectives, Physics Procedia, 78, 24-34, (2015)

[3] Bachmann, M., Gumenyuk, A., Rethmeier, M., Welding with high-power lasers: trends and developments, Physics Procedia, 83, 15-25, (2016)

[4] Wilson H.A., On convection of heat, Proceedings of the Cambridge Philosophical Society, 12, 406-423, (1904)

[5] Rosenthal, D., The theory of moving sources of heat and its application of metal treatments, Trans. ASME 68, 849-866, (1946)

[6] Rykalin, N.N., Calculation of heat flow in welding. Translated by Zvi Paley and CM Adams, Jr., Contact Number UC-19-066-001-C3817, (1951)

[7] Rykalin, N.N., Die Wäermegrundlagen des Schweissvorganges. Verlag Technik, Berlin (1952)

[8] Rykalin, N. N., Berechnung der Wäermevorgaenge beim Schweissen. VEB Verlag Technik, Berlin (1958)

[9] Karkhin V. A., Pilipenko A. Yu., Modelling thermal cycles in the weld metal and the heat affected zone in beam methods of welding thick plates, Welding International, 11(5), 401-403 (1997)

[10] Carslaw H. S., Jaeger J. C., Conduction of heat in solids. Oxford University Press, London (1973)

[11] Goldak, J., Chakravarti, A., Bibby, M., A new finite element model for welding heat sources, Metall. Mater. Trans. B 15 (2), 299-305, (1984)

[12] Karkhin V. A., Khomich P. N., Michailov V. G., Models for volume heat sources and functional-analytical technique for calculating the temperature fields in butt welding, Mathematical Modelling of Weld Phenomena 8, Graz: Verlag der Technischen Universitaet Graz, 819-834 (2007) 
[13] Chukkan, J.R., Vasudevan, M., Muthukumaran, S., Kumar, R.R., Chandrasekhar, N., Simulation of laser butt welding of AISI 316L stainless steel sheet using various heat sources and experimental validation, J. Mater. Process. Technol. 219, 48-59 (2015)

[14] Pittner A., Karkhin V., Rethmeier M., Reconstruction of 3D transient temperature fields for fusion welding processes on basis of discrete experimental data, Welding in the World, 59(4), 497-512 (2015)

[15] Lankalapalli K. N., Tu J. F., Gartner M., A model for estimating penetration depth of laser welding processes, Journal of Physics D: Applied Physics, 29, 1831-1841 (1996)

[16] Radaj D., Welding residual stresses and distortion. Calculation and measurement. DVS-Verlag, Düsseldorf (2003)

[17] Artinov, A., Bachmann M., Rethmeier M., Equivalent heat source approach in a 3D transient heat transfer simulation of full-penetration high power laser beam welding of thick metal plates, International Journal of Heat and Mass Transfer, 122, 1003-1013 (2018)

[18] Basu, B., Date, A. W., Numerical study of steady state and transient laser melting problems-I, Characteristics of flow field and heat transfer, International Journal of Heat and Mass Transfer, 33(6), 1149-1163, (1990)

[19] Yang,L.X., Peng, X.F., Wang, B.X., Numerical modeling and experimental investigation on the characteristics of molten pool during laser processing, International Journal of Heat and Mass Transfer, 44(23), 4465-4473, (2001)

[20] Kumar, A., DebRoy. T., Heat transfer and fluid flow during gas-metal-arc fillet welding for various joint configurations and welding positions, Metallurgical and Materials Transactions A38.3, 506-519 (2007)

[21] Piekarska, W., Kubiak, M., Three-dimensional model for numerical analysis of thermal phenomena in laser-arc hybrid welding process, International Journal of Heat and Mass transfer, 54(23), 4966-4974, (2011)

[22] Le Guen, E., Carin, M., Fabbro, R., Coste, F., Le Masson, P., 3D heat transfer model of hybrid laser Nd: Yag-MAG welding of S355 steel and experimental validation, International Journal of Heat and Mass Transfer, 54(7), 1313-1322, (2011) 
[23] Cho, W. I., Na, S. J., Thomy, C., Vollertsen, F., Numerical simulation of molten pool dynamics in high power disk laser welding, Journal of Materials Processing Technology, 212(1), 262-275 (2012)

[24] Zhang, L. J., Zhang, J. X., Gumenyuk, A., Rethmeier, M., Na, S. J., Numerical simulation of full penetration laser welding of thick steel plate with high power high brightness laser, Journal of materials Processing Technology, 214(8), 1710-1720, (2014)

[25] Pang, S., Chen, X., Zhou, J., Shao, X., Wang, C., 3D transient multiphase model for keyhole, vapor plume, and weld pool dynamics in laser welding including the ambient pressure effect, Opt. Lasers Eng. 74, 47-58 (2015)

[26] Ai, Y., Jiang, P., Shao, X., Li, P., Wang, C., A three-dimensional numerical simulation model for weld characteristics analysis in fiber laser keyhole welding, International Journal of Heat and Mass Transfer 108, 614-626 (2017)

[27] Pavelic V., Tanbakuchi R., Uyehara O. A., Myers P. S., Experimental and computed temperature histories in gas tungsten-arc welding of thin plates, Welding Journal, 7, 295-305 (1969)

[28] Radaj, D., Häuser, H., Braun, S., Numerische Simulation von Eigenspannungen und Verzug bei Schweißverbindungen aus AlMgSi-Legierungen, Konstruktion 50(7-8), 31-37 (1998)

[29] Karkhin V. A., Plochikhine V. V., Ilyin A. S., Bergmann H. W., Inverse modelling of fusion welding processes, Welding in the World, 46(11/12), 213 (2002)

[30] Karkhin V. A., Pittner A., Schwenk C., Rethmeier M., Simulation of inverse heat conduction problems in fusion welding with extended analytical heat source models, Frontiers of Materials Science, 5(2), 119-125 (2011)

[31] Faber, T.E., Fluid Dynamics for Physicists. Cambridge University Press, (1995)

[32] D.C. Wilcox, Turbulence Modeling for CFD, vol. 2, DCW Industries, La Canada, CA, 103-217 (1998)

[33] Bachmann, M., Avilov, V., Gumenyuk, A., Rethmeier, M., About the influence of a steady magnetic field on weld pool dynamics in partial penetration 
high power laser beam welding of thick aluminium parts, International Journal of Heat and Mass Transfer, 60, 309-321, (2013)

[34] Brent, A.D., Voller, V.R., Reid, K.T.J., Enthalpy-porosity technique for modeling convection-diffusion phase change: application to the melting of a pure metal, Numer. Heat Transf., Part A Appl. 13 (3), 297-318 (1988)

[35] Larsson, J., Numerical simulation of turbulent flows for turbine blade heat transfer applications, Chalmers University of Technology (1998)

[36] Kim, Y. D., Kim, W. S., A numerical analysis of heat and fluid flow with a deformable curved free surface in a laser melting process. International Journal of Heat and Fluid Flow, 29(5), 1481-1493, (2008)

[37] Banerjee P. K., Butterfield R., Boundary element methods in engineering science. McGraw-Hill Book Co, London (1981)

[38] Karkhin, V. A. Thermal processes in welding, -2nd ed. St. Petersburg: St. Petersburg Polytechnic University Publishing (2015)

[39] Radaj D., Heat effects of welding. Temperature field, residual stress, distortion. Springer - Verlag, Berlin (1992)

[40] Hang M., Okada A., Computation of GMAW welding heat transfer with boundary element method, Advances in Engineering Software, 16, 1-5 (1993)

[41] Brebbia C. A., Walker S., Boundary element techniques in engineering. Newnes - Butterworths (1980)

[42] Brebbia C. A., Telles J. C. F., Wrobel L. C., Boundary elements techniques. Theory and applications in engineering. Springer, Berlin (1984)

[43] Richter, F., Physikalische Eigenschaften von Stählen und ihre Temperaturabhängigkeit Stahleisen-Sonderbericht Heft 10, (1983)

[44] Sahoo, P., DebRoy, T., McNallan, M.J., Surface tension of binary metalsurface active solute systems under conditions relevant to welding metallurgy, Metall. Mater. Trans. B 19 (3), 483-491 (1988)

[45] Mills, K.C., Recommended Values of Thermophysical Properties for Selected Commercial Alloys. Woodhead Publishing, (2002) 
[46] ESI Group, Material database (2009)

[47] Bakir, N., Artinov, A., Gumenyuk, A., Bachmann, M., Rethmeier, M., Numerical simulation on the origin of solidification cracking in laser welded thickwalled structures, Metals, (2018) 